\title{
Eutrophication governs predator-prey interactions and temperature effects in Aedes aegypti populations
}

Louie Krol ${ }^{1,2}$, Erin E. Gorsich ${ }^{3,4}$, Ellard R. Hunting ${ }^{5,6}$, Danny Govender ${ }^{7,8}$, Peter M. van Bodegom and Maarten Schrama ${ }^{1,2^{*}}$ (1)

\begin{abstract}
Background: Mosquito population dynamics are driven by large-scale (e.g. climatological) and small-scale (e.g. ecological) factors. While these factors are known to independently influence mosquito populations, it remains uncertain how drivers that simultaneously operate under natural conditions interact to influence mosquito populations. We, therefore, developed a well-controlled outdoor experiment to assess the interactive effects of two ecological drivers, predation and nutrient availability, on mosquito life history traits under multiple temperature regimes.

Methods: We conducted a temperature-controlled mesocosm experiment in Kruger National Park, South Africa, with the yellow fever mosquito, Aedes aegypti. We investigated how larval survival, emergence and development rates were impacted by the presence of a locally-common invertebrate predator (backswimmers Anisops varia Fieber (Notonectidae: Hemiptera), nutrient availability (oligotrophic vs eutrophic, reflecting field conditions), water temperature, and interactions between each driver.

Results: We observed that the effects of predation and temperature both depended on eutrophication. Predation caused lower adult emergence in oligotrophic conditions but higher emergence under eutrophic conditions. Higher temperatures caused faster larval development rates in eutrophic but not oligotrophic conditions.

Conclusions: Our study shows that ecological bottom-up and top-down drivers strongly and interactively govern mosquito life history traits for Ae. aegypti populations. Specifically, we show that eutrophication can inversely affect predator-prey interactions and mediate the effect of temperature on mosquito survival and development rates. Hence, our results suggest that nutrient pollution can overrule biological constraints on natural mosquito populations and highlights the importance of studying multiple factors.
\end{abstract}

Keywords: Ecological drivers, Vector-borne, Anthropogenic pressures, Interaction effects, Temperature, Biodiversity decline

\footnotetext{
*Correspondence: m.j.j.schrama@cml.leidenuniv.nl

${ }^{1}$ Institute of Environmental Sciences, Leiden University, Leiden, The

Netherlands

Full list of author information is available at the end of the article
} 


\section{Background}

Mosquitoes are important disease vectors globally, and as such, mosquito population dynamics receive substantial significant scientific attention [1-4]. Although it is widely acknowledged that mosquito population dynamics are driven by large-scale climatological conditions (temperature, precipitation) $[5,6]$, there is a growing awareness that mosquitoes inhabit complex ecosystems and are, therefore, exposed to a myriad of biotic factors (bottom-up, e.g. resource availability and top-down, e.g. predation) that also influence the success of mosquitopopulations [7-10]. Accurate information on mosquito population dynamics has been shown to improve predictions of the timing, likelihood, or location of mosquito borne-disease outbreaks $[2,3,11]$. It is, therefore, crucial to understand both the local ecological context and largescale climatological conditions in which disease transmitting mosquito vector populations thrive.

Previous studies have demonstrated that eutrophication and predation can present important bottom-up and top-down controls of local mosquito populations $[8,10$, 12]. Eutrophication and the resulting increase in food availability for mosquito larvae increases their developmental rates, thus promoting higher numbers of adults emerging from temporary ponds [12, 13]. In contrast, the presence of predators can diminish population sizes of their prey $[10,12,14]$. For instance, a number of species belonging to Hemiptera prey on Aedes aegypti larvae [15-17]; their introduction in car tires and other artificial Ae. aegypti breeding habitats can reduce adult mosquito abundances by $95 \%$ after one year [18]. Although the separate effects of eutrophication and predation on mosquito populations is well known, mounting evidence from alternative systems highlights the importance of studying their combined consequences of mosquito populations. Interactions between multiple ecological drivers can modify not only the strength but also the direction of outcomes at the population or community level [19, 20] and ecological change is often associated with shifts in more than one potential driver. Taken together, this implies that it is essential to study multiple biotic and abiotic drivers of mosquito populations simultaneously under the highest possible degree of natural realism.

The mosquito Ae. aegypti is one of the most widespread vector species worldwide [6] and is able to transmit a wide range of viral pathogens such as chikungunya, yellow fever, Zika, dengue and Rift Valley fever (e.g. [21]). While container habitats in urbanized areas (flower vases, buckets with stored tap water, jerry cans, car tires) are generally considered to be the predominant hatching sites of Ae. aegypti [22], source population in natural and rural sites adjacent to urbanized areas present another class of environments where they can be found in high abundances [23, 24]. Habitats include mud pots, rock pools, large dead leaves, bromeliads, and tree holes, which sometimes contain large amounts of leaf litter and varying sources of pollution [23, 25-28]. These habitat classes vary not only in their inherent food availability, but also in abundance of predators [29, 30]. Pan-globally, natural predators of Ae. aegypti (e.g. various Anisops spp.) occur in a wide variety of temporary habitats that exhibit varying levels of nutrients [31, 32]. As such, natural populations of Ae. aegypti are simultaneously governed by both nutrients and predators. Here, we use $A e$. aegypti in a novel, well-controlled outdoor mesocosm setup to assess the interactive effects of eutrophication and predation on mosquito populations under four different temperature regimes.

\section{Methods}

Study design

The experiment was conducted between 5th and 19th May 2017 in 48 mesocosms at an outside, fenced facility at Skukuza, Kruger National Park, South Africa. Each of the mesocosms consisted of a 48-litre polyethylene tub, which was dug $20 \mathrm{~cm}$ into the soil and wrapped with tin foil to prevent heating. A 12-litre bucket was fitted into it, which was filled with 5 litres of rain water (Fig. 1a). This design was developed to prevent the absorption of external heat and enables a buffered micro-climate and precise temperature control in the inside buckets (Fig. 1b). The entire experimental area was covered with $80 \%$ shade cloth (Fig. 1c). Prior to setting up the treatments, all 12-litre inside buckets were rinsed thrice, using 1 litre of dechlorinated tap water. Five litres of dechlorinated tap water were added to the 12-litre internal buckets. All mesocosms were covered with mesh $(\varnothing 1 \mathrm{~mm})$ to prevent animal escapes or introductions.

\section{Rearing of mosquito larvae}

To cultivate sufficient numbers of larvae, roughly 4000 Ae. aegypti eggs were distributed over 5 small white plastic containers $(15 \times 10 \times 12 \mathrm{~cm})$. One day after hatching, larvae were fed once, using a modified version of the protocol by Zheng et al. [33]. In short, $250 \mathrm{mg}$ of Mnanti beer powder was mixed with $0.7 \mathrm{l}$ of chloride-free water. Each small container included approximately 800 eggs and received $125 \mathrm{ml}$ of this mixture. After six days at $20{ }^{\circ} \mathrm{C}$ and a natural day-night light regime, larvae were transferred to the mesocosms.

\section{Treatments}

A mix of first and second instar mosquito larvae (25 individuals) were exposed to a full factorial design including temperature (4 levels: ambient temperature and three treatments at progressive increments), eutrophication 

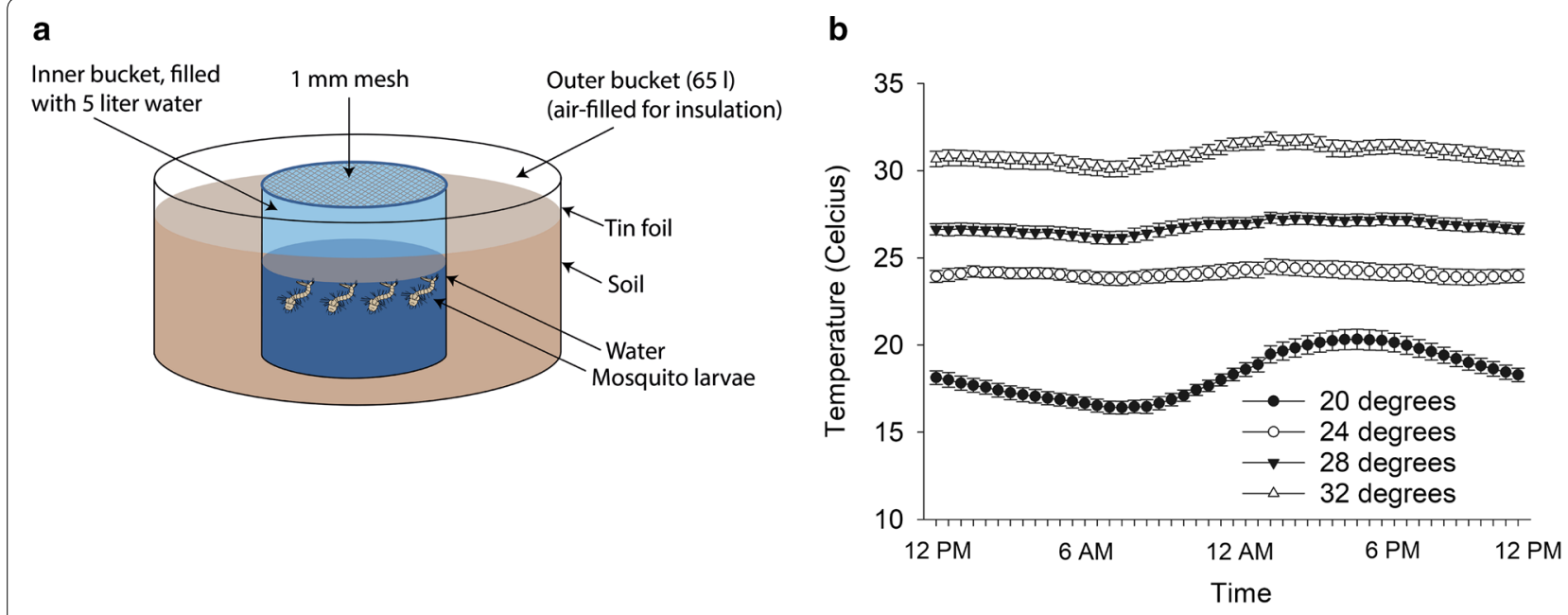

C

$$
\text { d }
$$
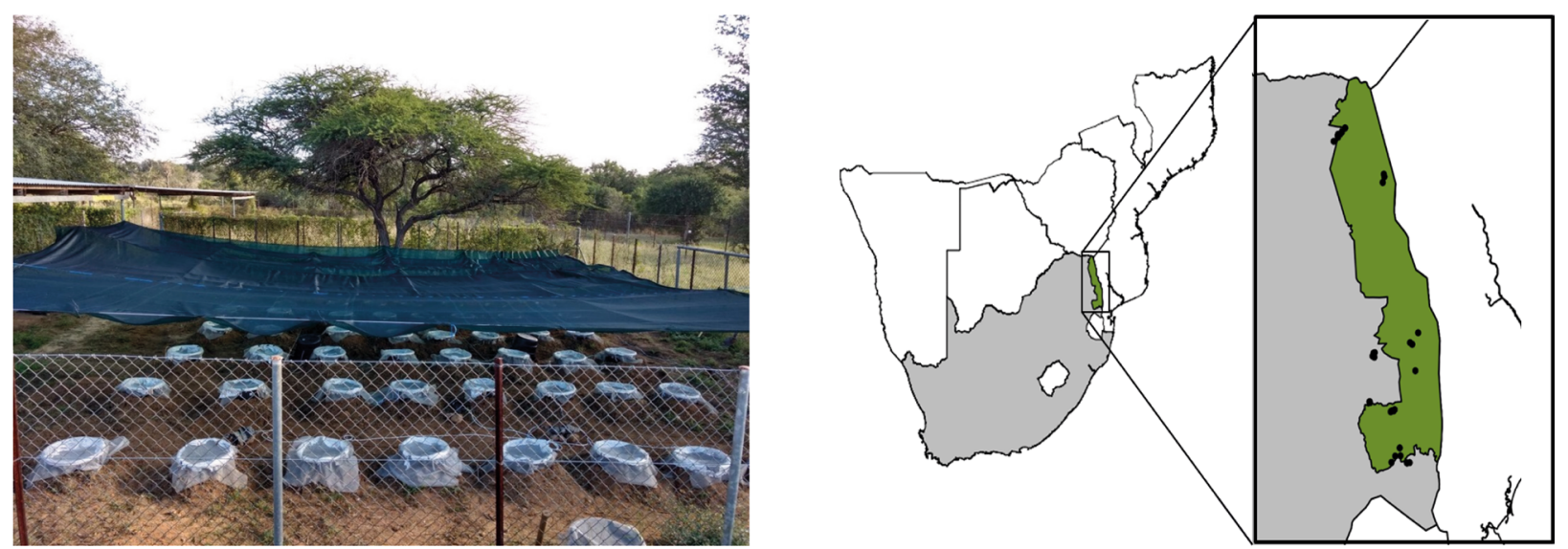

Fig. 1 Setup of the mesocosm experiment in Skukuza, Kruger National Park. a Schematic drawing of a mesocosm, courtesy of Erik-Jan Bosch. b Mean temperatures in each of the temperature treatments \pm standard error (SE), as measured with i-buttons in the different mesocosms during the entire period of the mesocosm experiment. Except for the lowest temperature treatment, all treatments contained aquarium heaters. c Overview of the setup. $\mathbf{d}$ Locations in and around Kruger National Park (indicated with red dots) where concentrations of inorganic phosphorus were measured to determine the median eutrophication status for the experiment

(2 levels, oligotrophic/eutrophic) and predation (2 levels, present/absent). This amounted to 16 different treatments in triplicate $(n=48)$. Within each of the three blocks all 16 treatments were randomized (Additional file 1: Figure S1).

\section{Temperature}

Four temperature regimes were created using aquarium heaters (50W, Aquadistri UK Ltd., Great Gransden, UK), which were placed at an angle of 30 degrees. The treatment with no heaters reflected the ambient temperature. Heaters were set to respectively 24,28 and $32{ }^{\circ} \mathrm{C}$ six days prior to adding the mosquito larvae and were slightly adjusted in the days after to ensure that temperatures within each mesocosm reflected the desired treatment value. Temperature was monitored throughout the study period using i-buttons (Maxim Corp., San Jose, USA). The average mesocosm temperature in this experiment was calculated by taking the mean across days and replicate mesocosms (Fig. 1b). This resulted in mean temperatures of $18.4,24.1,26.8$ and $30.9^{\circ} \mathrm{C}$.

\section{Eutrophication}

To set up eutrophication levels that mimicked those in water bodies in and around Kruger National Park, inorganic phosphorus was measured in 36 locations between 18th March and 7th May 2017 (Fig. 1d). The median levels of inorganic phosphorus in eutrophic natural water 
bodies was $1.025 \mathrm{mg} \mathrm{l}^{-1}$, as determined using a photospectrometer (Spectroquant Nova 60; Merck, Darmstadt, Germany) using a phosphate cell test for $0.05-5.0 \mathrm{mg} \mathrm{l}^{-1}$ $\mathrm{PO}_{4}{ }^{2-}$. To mimic these levels, we used a slurry of tap water and impala faeces (Aepyceros melampus Petersi). A calibration curve was constructed to calculate the amount of faeces needed to mimic the median concentration in natural situations (Additional file 1: Figure S2). The eutrophication treatment mesocosms were spiked with the impala faeces-based slurry one day prior to the addition of mosquito larvae ( $t=0$ days). To determine effectiveness of the treatments, phosphate $\left(\mathrm{PO}_{4}\right)$ and nitrate $\left(\mathrm{NO}_{3}\right)$ concentrations were measured in the mesocosms $(t=12$ days $)$ using a similar procedure as described above. In mesocosms not receiving the eutrophication treatment, the so-called oligotrophic treatment, no food was added to mimic rainwater fed breeding containers with realistic nutrient availability [12].

\section{Predation}

Predation pressure was investigated by adding one adult Anisops varia Fieber (Hemiptera: Notonectidae) to half of the mesocosms one day after the mosquito larvae had been added $(t=2)$. This species is a common freshwater invertebrate carnivore species in South Africa in a variety of water types, including container habitats [32], which, like other Notonectidae species, has a feeding preference for mosquito larvae and other small invertebrates in the water column [34]. Individuals $(n=24)$ were collected from a nearby temporary pond. We focused on this species because other well-known predators of mosquito lar vae such as Belastomitidae (Diplonychus sp.) or Culicidae (Toxorhynchites sp.) were not present in the area. In five mesocosms, predators died during the experiment and were replaced the same day. During the experiment, three $A$. varia individuals were observed on top of the mesh covering the mesocosms (Fig. 1a) in an apparent attempt to colonize the mesocosms, thus highlighting their ability to colonize such temporal ponds.

\section{Mosquito life history parameters}

Emergence of the first Ae. aegypti male was observed 4 days after the experiment started, after which we recorded the number of emerged adult mosquitoes from all mesocosms on a daily basis. The daily number of emerging adults was assessed using a manual aspirator. Newly emerged mosquitoes were sexed and counted. The experiment was terminated at $\mathrm{t}=19$ days because the majority of adults generally emerge at temperatures above $20{ }^{\circ} \mathrm{C}$ [35]. However, some mesocosms still contained a fraction of the pupae and larvae, which we expected to be an effect of the experimental conditions.
At $\mathrm{t}=19$ days, water was filtered using a plankton net (Ø $0.5 \mathrm{~mm}$ ) to count the remaining Ae. aegypti larvae and pupae in the mesocosms. We present the cumulative number of emerged male and female adult mosquitoes at $\mathrm{t}=14$ days and average larval development rate at day 14. The average larval development rate was calculated as $1 /$ (average number of days until between egg and emergence of a given mesocosm) and daily survival was calculated as $1 /$ (number of emerged adults/number of counted larvae at $\mathrm{t}=14$ days of a given mesocosm). Because some mesocosms had no adults emerging or larvae/pupae remaining at the termination of the experiment, we were also interested in how the treatments affected these parameters.

\section{Data analysis}

First, we explored the effectiveness of the temperature, eutrophication and predation treatments on abiotic factors in the mesocosms. To confirm that the temperature treatments were effective, we tested the temperature differences between the four temperature regimes with a one-way ANOVA and a post hoc Tukey test. The dependent variable was the average temperature value for each mesocosm across the study. Differences in abiotic factors (phosphate concentration (PO4), nitrate concentration $\left(\mathrm{NO}_{3}\right), \mathrm{pH}$, total dissolved salts and electrical conductivity (EC)) were tested with a general linear model with categorical variables representing each mesocosm's temperature treatment (4 levels, see above), predation treatment (2 levels: present/absent), eutrophication treatment (2 levels: oligotrophic/eutrophic) and their 2-way interactions as a fixed factor.

Secondly, we explored the effects of temperature, eutrophication and predators and their interactions on seven Aedes-related outcomes at $\mathrm{t}=19$. These were: (i) cumulative number of emerged male adult mosquitoes at $t=19$; (ii) cumulative number of emerged female adult mosquitoes at $t=19$; (iii) total cumulative number of emerged adults; (iv) whether or not any adults emerged before $\mathrm{t}=19$ (yes/no); (v) development rate (1/days between egg and emergence); (vi) number of remaining larvae and pupae at $\mathrm{t}=19$; and (vii) whether or not larvae or pupae remained at $t=19$ (yes/no).

Effects of eutrophication, temperature and predation on each outcome were tested with linear models and post hoc Tukey HSD tests and their 2-way interactions as fixed factors. Block was added as a random variable. Effects of the experimental treatments on the odds that larvae survived and adults emerged were tested in two separate analyses using a logistic regression model with the odds of emergence as binomial response variables and the experimental treatments (eutrophication, predation and 
temperature) as fixed factors. Block was again included as a random variable.

\section{Results}

\section{Experimental conditions}

Analyses of abiotic conditions support the validity of our outdoor experimental design. Mesocosms that received the eutrophication treatment contained higher concentrations of phosphorus $\left(\mathrm{PO}_{4}\right)$, but there was no difference in nitrate $\left(\mathrm{NO}_{3}\right)$ concentrations (Fig. 2). Moreover, there was no significant effect of eutrophication on EC, total dissolved salt or pH (Fig. 2). We found no effect of predation on any of the abiotic factors. Temperature was significantly different among temperature treatments (Fig. 1b) and significant effects were observed for some abiotic factors. The two highest temperate treatments had a higher EC and total dissolved salts, but we found no effect of temperature on nutrient concentrations $\left(\mathrm{PO}_{4}, \mathrm{NO}_{3}\right)$ and $\mathrm{pH}$ (Fig. 2). Moreover, there were no significant interaction effects between treatments for each of the abiotic factors.

In 12 mesocosms, no emergence of mosquitoes occurred, 11 of which belonged to the oligotrophic treatment. These 12 mesocosms were excluded from the calculations on development rate but were included in the analyses of adult emergence and the number of larvae remaining.

\section{Effects on adult emergence}

The number of emerged adults ranged from 0 to 25, resulting in average emergence of 6.9 individuals $( \pm \mathrm{SD}$ 6.5). The cumulative number of adult mosquitoes which had emerged from a mesocosm at $\mathrm{t}=19$ was affected by the interaction between eutrophication and predation $\left(F_{(1,36)}=6.0, P=0.02\right.$; Fig. 3). Predation in oligotrophic conditions resulted in a $60 \%$ decrease in adult emergence, whereas predation in eutrophic conditions resulted in a $30 \%$ increase of adult emergence (Fig. 3). The number of emerging adult mosquitoes was also affected by temperature $\left(F_{(3,36)}=3.8, P=0.02\right.$; Additional file 1: Table S1), with the highest number of mosquitoes emerged at intermediate temperatures (Additional file 1: Figure S3). Of the 12 mesocosms where no adult emergence was observed, six were of the lowest temperature treatment, four were exposed to the highest temperature and one belonged to each of the intermediate temperature
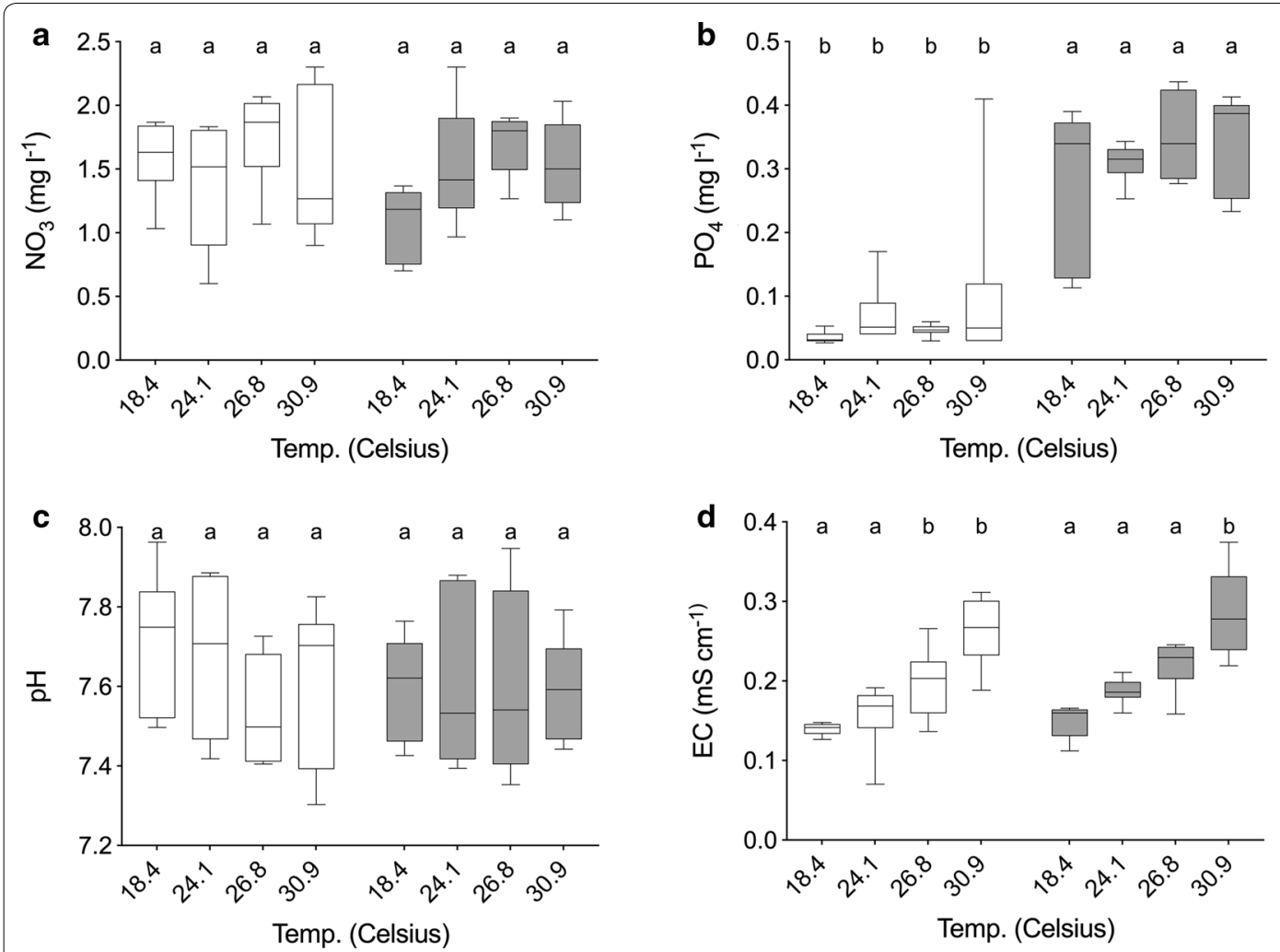

Oligotrophic Eutrophic

Fig. 2 Overview of eutrophication variables $(\mathbf{a}, \mathbf{b})\left(\mathrm{NO}_{3}, \mathrm{PO}_{4}\right)$ and abiotic variables $(\mathbf{c}, \mathbf{d})$ : $\mathrm{pH}$; tds, total dissolved salts; EC (mV), electro conductivity in $\mathrm{mS}$ per $\mathrm{cm}$. All data shown as the mean \pm standard error (SE). Treatments with and without predators were merged in this table. Different letters indicate significant differences between treatments at $\mathrm{a}=0.05$ 


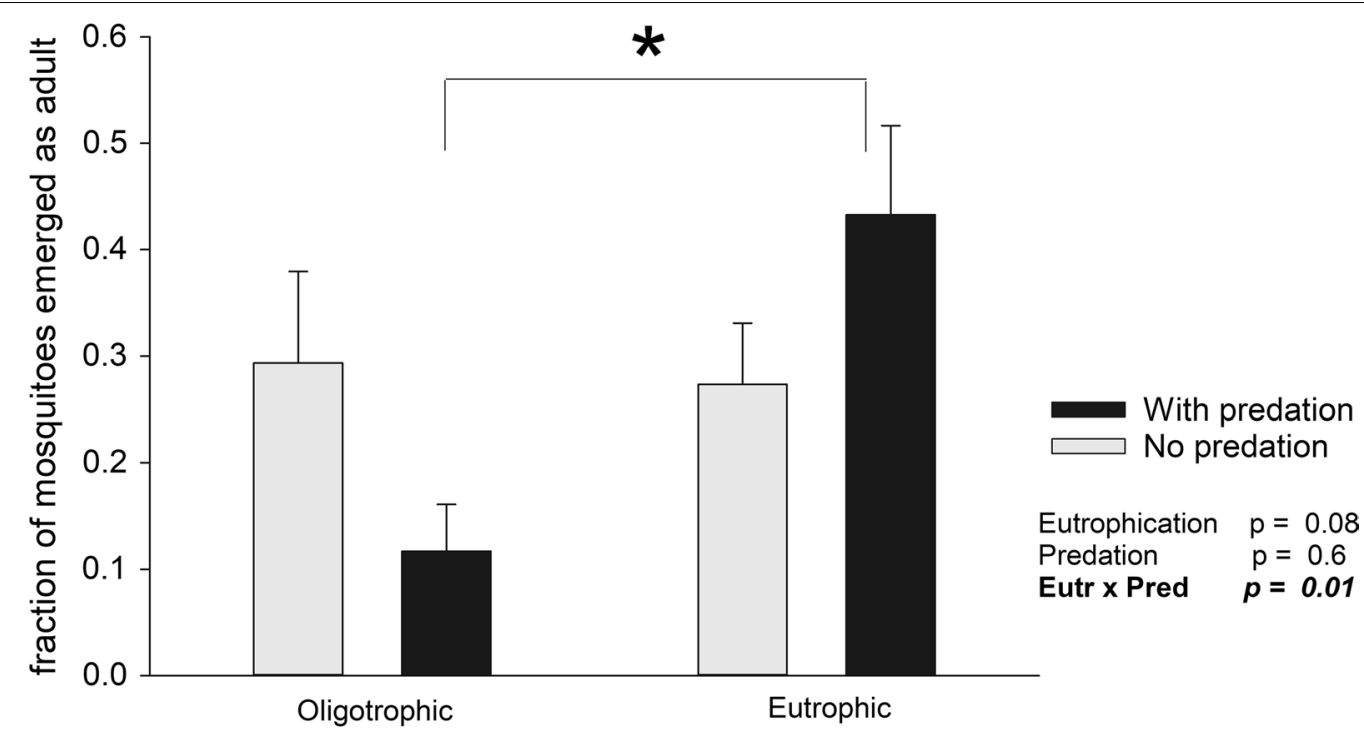

Treatment

Fig. 3 Effect of eutrophication and predation as interacting pressures on emergence of adult Ae. aegypti. Bars indicate average cumulative emergence across all temperature regimes \pm standard error (SE). Although there was a significant effect of temperature influencing the number of adults emerged, there were no significant interactions between temperature and eutrophication/predation, such that the pattern shown in the figure is representative across temperature treatments. Fractions are shown for illustration purposes only; statistics were done on the cumulative number of emerged adults. Star indicates a significant difference at $a=0.05$

treatments $\left(24\right.$ and $\left.28{ }^{\circ} \mathrm{C}\right)$, suggesting a negative effect of high and low temperatures on adult emergence.

We found a positive effect of eutrophication (Wald Stat $=6.9, P=0.010)$ and a significant interaction effect (Wald Stat $=4.9, P=0.038$ ) between predation and eutrophication on the odds that females emerged and a positive effect of temperature on the odds that females emerged (Wald Stat $=4.8, P=0.028$; Fig. $4 \mathrm{a}$ ). The odds that males emerged, which happens in general 1-2 days before females emerge, was significantly and positively

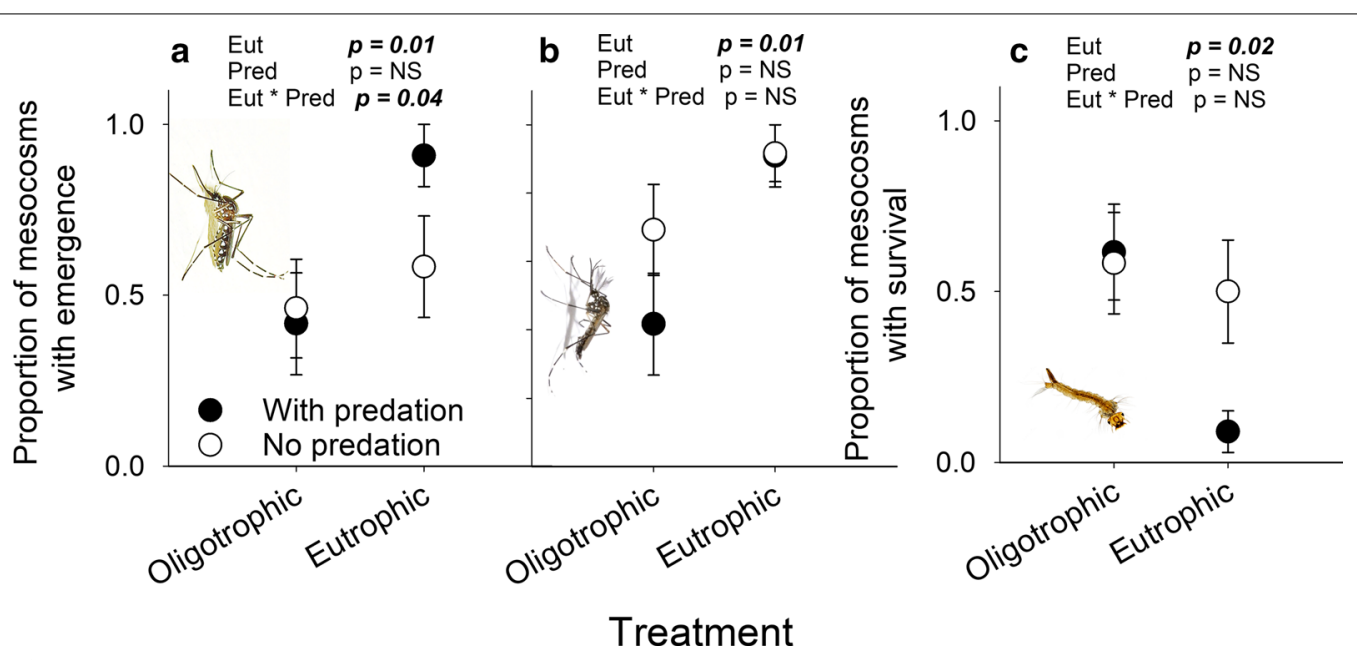

Fig. 4 Effect of eutrophication and predation treatments on the odds of emergence of females (a), emergence of males (b) and larval survival (c). Statistics shown above each of the panels depict results from a logistic regression model. Each symbol represents the average across all temperature regimes. NS indicates $P>0.05$ 
affected by eutrophication (Wald Stat $=6.8, P=0.009$; Fig. 4 b) and not by temperature or predation (Fig. 4b).

\section{Effects on development rate}

The time to emergence ranged between 9 and 19 days, with an average 13.9 days ( \pm SD 3.16). We found no significant effect of predation on development rate. However, there was a significant effect of eutrophication $\left(F_{(1,21)}=8.7, P=0.007\right)$, an effect of temperature $\left(F_{(3,21)}=5.8, P=0.005\right)$, and a significant interaction effect between eutrophication and temperature $\left(F_{(3,21)}=7.7\right.$, $P=0.004)$ on development rate. The association between development rates and temperature was stronger under eutrophic conditions than under oligotrophic conditions (Fig. 5a, b).

\section{Effects on surviving larvae}

On average, $12.9 \%$ ( \pm SE $3.3 \%)$ of the larvae remained in the mesocosms (i.e. survived as larvae and did not emerge as adults) after the experiment was terminated at $\mathrm{t}=19$. The odds that larvae remained in the mesocosms until the end of the experiment was lower under eutrophic conditions (Wald Stat $=5.6, P=0.018$ ) and higher temperatures (Wald Stat $=5.2, P=0.023$ ), but was not significantly affected by predation (Wald Stat $=2.1, P=0.15$ ) or by the interaction between predation and eutrophication (Wald Stat $=0.3, P=0.6$ ) (Fig. 4c). In mesocosms with the highest temperature regime only $2.5 \%( \pm \mathrm{SE} 1.8 \%)$ of the mosquitoes remained in a larval stage at the end of the experiment, whereas the lowest temperature treatment had $30.3 \%$ ( \pm SE $10.3 \%$ ) of the mosquitoes remaining as larvae.

\section{Discussion}

In this study, we used a novel outdoor experimental approach to assess the single and interactive effects of three important ecological drivers (predation, eutrophication, temperature) on mosquito larval development rate, adult emergence and larval survival. Our results were collected under a semi-realistic setting representing realistic variation in food availability for larval mosquitos (eutrophic vs oligotrophic) and the presence or absence of invertebrate predation. We found evidence for strong interactive effects between all three drivers: (i) negative effects of predation on adult mosquito emergence depended on the eutrophication conditions; (ii) positive effects of temperature on larval development rates depend on the eutrophication conditions; (iii) adult emergence was affected independently by temperature, eutrophication and its interaction with predation; but (iv) larval survival was only affected by eutrophication and not by temperature or predation.

Our study shows an interaction between predation and eutrophication on the total number of adult mosquitoes emerging as well as on the probability of emergence. There was a strong negative effect of predation on the emergence of adult mosquitoes, but the effect of predation only occurred in eutrophication treatments, thus suggesting that predators are effective in decreasing mosquito emergence in oligotrophic environments but may increase emergence in eutrophic habitats. The reason for this could be that predators consume the smaller prey first [36] and as such, provide an advantage to the larger larvae by decreasing negative density dependent effects such as interference competition. However, based on our results, we cannot exclude the possibility that $A$. varia is a less effective predator under eutrophic conditions,
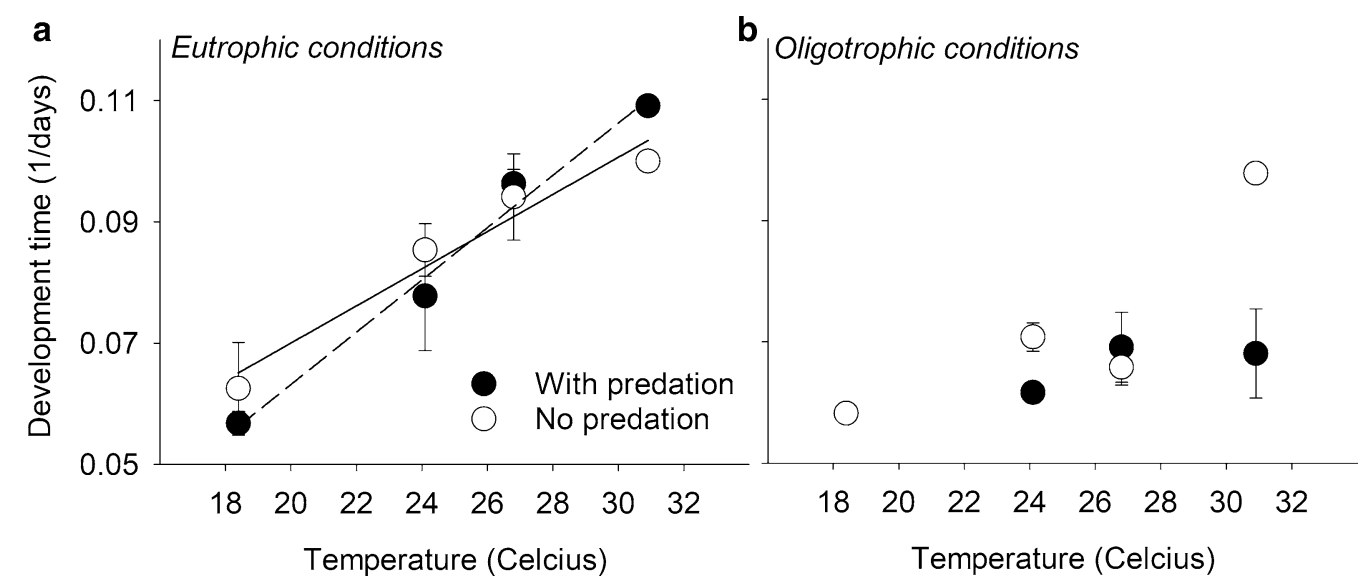

Fig. 5 Effect of eutrophication, temperature and predation on development rate of Aedes aegypti. a Results for eutrophic conditions. b Results for oligotrophic conditions. Fits in a are for illustrative purposes only 
although this does not seem very likely as the species has been naturally observed in all ponds within the measured range of nutrients. Another possibility is that the larvae react to the presence of predation by modifying their behaviour [37], increasing their trophic activity which decreases the development time needed to reach the adult stage [38]. Whether this interaction between eutrophication and predation is similar for other predators and holds across a range of eutrophication regimes warrants further study. Nevertheless, because breeding habitats of Ae. aegypti are often oligotrophic [22, 23], it is likely that predators capable of colonizing these, such as backswimmers like $A$. varia, can play an important role in lowering mosquito numbers of those species under such conditions. However, in habitats with high nutrient pollution, our results suggest that the opposite could occur, where predators increase adult emergence.

Previous studies on the dynamics of wild mosquito populations have highlighted the importance of density dependence (e.g. [39, 40]). Food abundance in breeding habitats may be one of the main ecological mechanisms responsible for density dependent effects [41]. In mosquito habitats where food abundance may be limiting larval growth, density dependent effects are likely to play a more important role than in experiments where food is added ad libitum (e.g. [42, 43]). Indeed, these results and our previous work on $C x$. pipiens [12] strongly suggest that the interaction between food abundance and temperature jointly shapes larval development rate, where development rate is fastest at higher temperatures and in eutrophic conditions where food is plentiful. Given that Ae. aegypti often breeds in rainwater or tap water fed containers (e.g. [23, 42]) under oligotrophic conditions, the higher temperatures predicted through global temperature forecast models [44] may not necessarily lead to greater Ae. aegypti population growth rates in those habitats. Mosquito populations may also be influenced through mechanisms not considered in this study such as the presence of confamiliar species, pesticide pollution, salinity and habitat drying [22]. Similar experiments like the one described in this paper are, therefore, required to investigate the interactive effects of other bottom-up and top-down drivers of both vector and non-vector mosquito species.

\section{Conclusions}

Here we used Ae. aegypti to specifically assess the interactive effects of eutrophication and predation on mosquito population dynamics under four different temperature regimes. We performed a controlled outdoor mesocosm experiment in Kruger Park, South Africa which allowed more natural realism than typically represented by laboratory-based studies. Although our experiment had a confined set of drivers and organisms and may thus overlook modulations from biotic and abiotic variables that would otherwise co-occur in natural ecosystems, results obtained in this study confirm that ecological bottom-up and top-down drivers incongruently govern mosquito population dynamics in Ae. aegypti. Specifically, depending on temperature, eutrophication can strongly alter mosquito population dynamics and can inversely affect predator-prey interactions. Our results thereby suggest that nutrient pollution can overrule and inverse biological constraints on natural mosquito abundances. This outcome poses great concerns about the consequences of ongoing release of nutrients in the environment for the dynamics of vector-borne disease.

\section{Additional file}

Additional file 1: Table S1. Results from the linear models on adult emergence (A) and development rate (B) and results from the binomial models on the probability of emergence of adult females (C) adult males (D) and the probability that larvae remained in the mesocoms at the end of the experiment (E) Significant effects are depicted in bold. Figure S1. Randomized treatments in the mesocosm experiment within each of the three blocks. Each of the 48 individual mesocosm is indicated with $\mathrm{S}$ followed by a number (1-48). T refers to the temperature regimes where 1 indicates the lowest temperature and 4 refers to highest temperature. E refers to eutrophication ( 0 : oligotrophic, 1: eutrophic) and $P$ refers to predation ( 0 is absent, 1 is present). Figure $\mathbf{S 2}$. Phosphorus calibration based on dissolved droppings of Impala (Aepyceros melampus): $y=0.0093 x+0.6374$ and $R^{2}=0.9084$. Using this formula, we calculated the amount of faeces water necessary to mimic the average observed in natural sites (1.025 mg/l). Figure S3. Relationship between temperature and larval survival $(\mathbf{a}, \mathbf{b})$ and adult emergence $(\mathbf{c}, \mathbf{d})$ under eutrophic $(\mathbf{a}$, c) and oligotrophic conditions (b, d). Black symbols ( \pm SE) refer to the predator treatments, open symbols refer to treatments without predators. Fits are shown for illustrative purposes only: solid lines indicate significant correlations, dotted lines indicate non-significant correlations. Goodnessof-fit and significance of the fit is given in the upper left corner of each of the panels.

\section{Acknowledgements}

We are grateful to Veterinary Wildlife Services (Ben Baloyi, Johan Malan) for accommodating us and allowing us to carry out the experiment at the Skukuza Boma. Brianna Beechler is gratefully acknowledged for assisting with setting up the experiments. Thanks also to Gijs van Nes, Karabo Moloi, Nondumiso Myataza, Nina Haver, and Vicky Beckers who have all provided indispensable help during the setting up of the experiment and collection of $\mathrm{N}$ and $\mathrm{P}$ measurements in the field. A special thanks goes to Purvance Shikwambana, who helped us with setting up the water analysis at the Skukuza laboratory. Finally, Erik-Jan Bosch is gratefully acknowledged for drawing Fig. 1a.

\section{Funding}

This study was supported by the Gratama Fund, Grant Number 2016.08, which was awarded to MS, supported by the Uyttenboogaart-Eliasen foundation for comparative entomology, Grant No. SUB.2016.12.08 and the RCN-IDEAS grant which was awarded to EEG. The funders had no role in study design, data collection and analysis, decision to publish, or preparation of the manuscript. 


\section{Availability of data and materials}

Data supporting the conclusions of this article are included within the article and its additional files. The datasets used and analysed during the present study are available from the corresponding author upon reasonable request.

\section{Authors' contributions}

LK, EG and MS conceived the idea for this experiment; LK set up the experiment and carried out the measurements together with MS and EG. DG hosted the experiment, commented on the setup and assisted during writing of the paper. EH and PB assisted with writing the manuscript. All authors read and approved the final manuscript.

\section{Ethics approval and consent to participate}

Not applicable. Ethical clearance was not needed for this study.

\section{Consent for publication}

Not applicable.

\section{Competing interests}

The authors declare that they have no competing interests.

\section{Publisher's Note}

Springer Nature remains neutral with regard to jurisdictional claims in published maps and institutional affiliations.

\section{Author details}

${ }^{1}$ Institute of Environmental Sciences, Leiden University, Leiden, The Netherlands. ${ }^{2}$ Naturalis Biodiversity Centre, Leiden, The Netherlands. ${ }^{3}$ The Zeeman Institute for Systems Biology \& Infectious Disease Epidemiology Research, University of Warwick, Coventry, UK. ${ }^{4}$ School of Life Sciences, University of Warwick, Coventry, UK. ${ }^{5}$ School of Biological Sciences, University of Bristol, Bristol, UK. ${ }^{6}$ Department of Biology, Woods Hole Oceanographic Institution, Woods Hole, MA, USA. ${ }^{7}$ Department of Paraclinical Sciences, University of Pretoria, Pretoria, South Africa. ${ }^{8}$ Scientific Services Kruger National Park, Skukuza, South Africa.

Received: 10 October 2018 Accepted: 4 April 2019 Published online: 24 April 2019

\section{References}

1. Murdock CC, Evans MV, McClanahan TD, Miazgowicz KL, Tesla B. Finescale variation in microclimate across an urban landscape shapes variation in mosquito population dynamics and the potential of Aedes albopictus to transmit arboviral disease. PLoS Negl Trop Dis. 2017;11:e0005640.

2. Beck-Johnson LM, Nelson WA, Paaijmans KP, Read AF, Thomas MB, Bjørnstad ON. The effect of temperature on Anopheles mosquito population dynamics and the potential for malaria transmission. PLoS ONE. 2013;8:e79276.

3. Beck-Johnson LM, Nelson WA, Paaijmans KP, Read AF, Thomas MB, Bjørnstad ON. The importance of temperature fluctuations in understanding mosquito population dynamics and malaria risk. R Soc Open Sci. 2017:4:160969.

4. Ewing DA, Cobbold CA, Purse BV, Nunn MA, White SM. Modelling the effect of temperature on the seasonal population dynamics of temperate mosquitoes. J Theor Biol. 2016:400:65-79.

5. Alto BW, Juliano SA. Precipitation and temperature effects on populations of Aedes albopictus (Diptera: Culicidae): implications for range expansion. J Med Entomol. 2001;38:646-56.

6. Kraemer MUG, Sinka ME, Duda KA, Mylne AQN, Shearer FM, Barker CM, et al. The global distribution of the arbovirus vectors Aedes aegypti and Ae. albopictus. Elife. 2015;4:e08347.

7. Reiter P. Climate change and mosquito-borne disease. Environ Health Perspect. 2001;109:141-61.

8. Lafferty KD. The ecology of climate change and infectious diseases. Ecology. 2009;90:888-900.

9. Young HS, Wood CL, Kilpatrick AM, Lafferty KD, Nunn CL, Vincent JR. Conservation, biodiversity and infectious disease: scientific evidence and policy implications. Philos Trans R Soc Lond B Biol Sci. 2017;372:20160124.
10. Chase JM, Knight TM. Drought-induced mosquito outbreaks in wetlands. Ecol Lett. 2003;6:1017-24.

11. Davis JK, Vincent G, Hildreth MB, Kightlinger L, Carlson C, Wimberly MC. Integrating environmental monitoring and mosquito surveillance to predict vector-borne disease: prospective forecasts of a West Nile virus outbreak. PLoS Curr. 2017. https://doi.org/10.1371/currents.outbr eaks.90e80717c4e67e1a830f17feeaaf85de.

12. Schrama M, Gorsich EE, Hunting ER, Barmentlo SH, Beechler B, Bodegom PMV. Eutrophication and predator presence overrule the effects of temperature on mosquito survival and development. PLoS Negl Trop Dis. 2018;12:e0006354.

13. Hagstrum DW, Workman EB. Interaction of temperature and feeding rate in determining the rate of development of larval Culex tarsalis (Diptera, Culicidae). Ann Entomol Soc Am. 1971;64:668-71.

14. Service MW. Mortalities of the immature stages of species B of the Anopheles gambiae complex in Kenya: comparison between rice fields and temporary pools, identification of predators, and effects of insecticidal spraying. J Med Entomol. 1977;13:535-45.

15. Wattal S, AdakT, Dhiman RC, Sharma VP. The biology and predatory potential of notonectid bug, Enithares indica (Fabr) against mosquito larvae. Southeast Asian J Trop Med Public Health. 1996;27:633-6.

16. Venkatesan P, Sivaraman S. Changes in the functional response of instars of Diplonychus indicus (Hemiptera: Belostomatidae) in its predation of 2 species of mosquito larvae of varied size. Entomon. 1984;9:191-6.

17. Neri-Barbosa JF, Quiroz-Martinez H, Rodriguez-Tovar ML, Tejada LO, Badii MH. Use of Bactimos briquets (Bti formulation) combined with the backswimmer Notonecta irrorata (Hemiptera: Notonectidae) for control of mosquito larvae. J Am Mosq Control Assoc. 1997;13:87-9.

18. Sivagnaname N. A novel method of controlling a dengue mosquito vector, Aedes aegypti (Diptera: Culicidae) using an aquatic mosquito predator, Diplonychus indicus (Hemiptera: Belostomatidae) in tyres. Dengue Bull. 2009;33:148-60.

19. Jackson MC, Loewen CJG, Vinebrooke RD, Chimimba CT. Net effects of multiple stressors in freshwater ecosystems: a meta-analysis. Glob Chang Biol. 2016;22:180-9.

20. Côté IM, Darling ES, Brown CJ. Interactions among ecosystem stressors and their importance in conservation. Proc R Soc B Biol Sci. 2016;283:20152592.

21. Leta S, Beyene TJ, De Clercq EM, Amenu K, Kraemer MUG, Revie CW. Global risk mapping for major diseases transmitted by Aedes aegypti and Aedes albopictus. Int J Infect Dis. 2018;67:25-35.

22. Christophers S. Aedes aegypti (L.) the yellow fever mosquito: its life history, bionomics and structure. London: The Syndics of the Cambridge University Press; 1960.

23. Getachew D, Tekie H, Gebre-Michael T, Balkew M, Mesfin A. Breeding sites of Aedes aegypti: potential dengue vectors in dire Dawa, east Ethiopia. Interdiscip Perspect Infect Dis. 2015;2015:706276.

24. Phong Vu T. Study on the Aedes larvae resources of dengue fever/haemorrhagic dengue fever in some regions during 1997-2000. J Pract Med. 2002;435:64-6.

25. Philbert A, ljumba JN. Preferred breeding habitats of Aedes aegypti (Diptera: Culicidae) mosquito and its public health implications in Dares Salaam, Tanzania. J Environ Res Manag. 2013:4:344-51.

26. Chadee DD, Ward RA, Novak RJ. Natural habitats of Aedes aegypti in the Caribbean-a review. J Am Mosq Control Assoc. 1998;14:5-11.

27. Simard F, Nchoutpouen E, Toto JC, Fontenille D. Geographic distribution and breeding site preference of Aedes albopictus and Aedes aegypti (Diptera: Culicidae) in Cameroon, Central Africa. J Med Entomol. 2005:42:726-31.

28. Babu CJ, Panicker KN, Das PK. Breeding of Aedes aegypti in closed septic tanks. Indian J Med Res. 1983;77:637.

29. Weterings $\mathrm{R}$, Umponstira C, Buckley HL. Predation rates of mixed instar Odonata naiads feeding on Aedes aegypti and Armigeres moultoni (Diptera: Culicidae) larvae. J Asia Pac Entomol. 2015;18:1-8.

30. Dida GO, Gelder FB, Anyona DN, Abuom PO, Onyuka JO, Matano AS, et al. Presence and distribution of mosquito larvae predators and factors influencing their abundance along the Mara River, Kenya and Tanzania. Springerplus. 2015:4:136.

31. Shaalan EAS, Canyon DV. Aquatic insect predators and mosquito control. Trop Biomed. 2009;26:223-61. 
32. Mabidi A, Bird MS, Perissinotto R. Distribution and diversity of aquatic macroinvertebrate assemblages in a semiarid region earmarked for shale gas exploration (Eastern Cape Karoo, South Africa). PLoS ONE. 2017;12:e0178559.

33. Zheng M-L, Zhang D-J, Damiens DD, Yamada H, Gilles JRL. Standard operating procedures for standardized mass rearing of the dengue and chikungunya vectors Aedes aegypti and Aedes albopictus (Diptera: (Culicidae)-I-egg quantification. Parasites Vectors. 2015;8:42.

34. Klecka J, Boukal DS. Who eats whom in a pool? A comparative study of prey selectivity by predatory aquatic insects. PLoS ONE. 2012;7:e37741.

35. Tun-Lin W, Burkot TR, Kay BH. Effects of temperature and larval diet on development rates and survival of the dengue vector Aedes aegypti in north Queensland, Australia. Med Vet Entomol. 2000;14:31-7.

36. Quiroz-Martínez H, Rodríguez-Castro A. Aquatic insects as predators of mosquito larvae. J Am Mosq Control Assoc. 2007;23:110-7.

37. Gimonneau G, Pombi M, Dabiré RK, Diabaté A, Mora S, Simard F. Behavioural responses of Anopheles gambiae sensu stricto M and S molecular form larvae to an aquatic predator in Burkina Faso. Parasites Vectors. 2012;5:65.

38. Diabate A, Dabiré RK, Heidenberger K, Crawford J, Lamp WO, Culler LE, Lehmann T. Evidence for divergent selection between the molecular forms of Anopheles gambiae: role of predation. BMC Evol Biol. 2008;8:5.
39. Yang GJ, Brook BW, Whelan PI, Cleland S, Bradshaw CJA. Endogenous and exogenous factors controlling temporal abundance patterns of tropical mosquitoes. Ecol Appl. 2008;18:2028-40.

40. Mulatti P, Ferguson HM, Bonfanti L, Montarsi F, Capelli G, Marangon S. Determinants of the population growth of the West Nile virus mosquito vector Culex pipiens in a repeatedly affected area in Italy. Parasites Vectors. 2014;7:26.

41. Rejmánková E, Grieco J, Achee N, Roberts DR. Ecology of larval habitats. In: Manguin S, editor. Anopheles mosquitoes-new insights into malaria vectors. London: Intech Open; 2013. p. 397-446.

42. Ciota AT, Matacchiero AC, Kilpatrick AM, Kramer LD. The effect of temperature on life history traits of Culex mosquitoes. J Med Entomol. 2014:51:55-62.

43. Loetti V, Schweigmann N, Burroni N. Development rates, larval survivorship and wing length of Culex pipiens (Diptera: Culicidae) at constant temperatures. J Nat Hist. 2011;45:2203-13.

44. Saleeza SNR, Norma-Rashid Y, Sofian-Azirun M. Mosquitoes larval breeding habitat in urban and suburban areas, peninsular Malaysia. Int J Biol Vet Agric Food Eng. 2011;5:72-6.
Ready to submit your research? Choose BMC and benefit from:

- fast, convenient online submission

- thorough peer review by experienced researchers in your field

- rapid publication on acceptance

- support for research data, including large and complex data types

- gold Open Access which fosters wider collaboration and increased citations

- maximum visibility for your research: over 100M website views per year

At BMC, research is always in progress.

Learn more biomedcentral.com/submissions 